\title{
Impact study of NOOR 1 project on the Moroccan territorial economic development
}

\author{
Amale Laaroussi ${ }^{1, *}$, Abdelrhani Bouayad ${ }^{1}$, Zakaria Lissaneddine ${ }^{2}$, and Lalla Amina Alaoui ${ }^{3}$ \\ ${ }^{1}$ Faculty of Legal, Economic and Social Sciences, Moulay Ismail University, Meknes, Morocco \\ ${ }^{2}$ National School of Business and Management, Moulay Ismail University, Meknes, Morocco \\ ${ }^{3}$ Faculty of Legal, Economic and Social Sciences Marrakech, Cadi Ayyad University, Morocco
}

Received: 24 February 2021 / Received in final form: 17 March 2021 / Accepted: 19 March 2021

\begin{abstract}
Morocco is one of the countries investing more and more in Renewable Energy (RE) technologies to meet the growing demand for energy and ensure the security of supply in this sector. The number of solar projects planned and implemented, as well as solar thermal projects in the form of Concentrating Solar Power (CSP) installations is steadily increasing. Many of these installations are designed as large utility systems. In order to provide strong evidence on local, regional and even national impacts, this article examines the impacts of largescale renewable energy projects on territorial development, based on a case study of the NOOR 1 (Concentrated Solar Power (CSP)) project in Ouarzazate, Morocco. The data collected during this study, conducted through semi-structured interviews with experts, stakeholders, local community representatives and combined with an analysis of documents provided by the NOOR 1 project managers, investors and consulting firms specialized in the field of Renewable Energy, provide detailed evidence on the type and magnitude of impacts on the economic development of the Moroccan southern region where the NOOR 1 plant is located. The data collected is analyzed using NVIVO software. The study results in a consolidated list of many impacts with varying levels of significance for different stakeholder groups, including farmers, youth, women, community representatives and small and medium firms owners. It should be noted that the importance of analyzing the economic impact of large infrastructure projects is widely recognized, but so far, there is little published in the academic and professional literature on the potential impacts of these projects at the local level. Even less information is available on the local impacts of large-scale project implementation in Morocco. While many macroeconomic studies have fed the recent surge in investment in RE projects with the promise of multiple social, economic, environmental, and even geopolitical benefits at the macro level, public debates and discussions have raised considerable doubts. The question of whether these promises would also leave their marks at the local level has also arisen. Despite these uncertainties, very few academics and practitioners have conducted research to empirically develop a good understanding of the impact of RE projects at the local level. To fill this research gap, the economic impact analysis of NOOR 1 provides a detailed empirical overview, which allows a better understanding of the effects that the infrastructure developments of Concentrated Solar Power (CSP) plants can have on the economic environment in which they are located.
\end{abstract}

\section{Introduction}

No one can ignore that the development of a nation depends largely on stable and sustainable energy production and supply. However, increased demand for fossil fuels to face energy-intensive Western lifestyles and the growth of emerging countries is raising energy prices [1] and calling into question the planet's ability to provide the energy

\footnotetext{
* e-mail: laaroussiamale5@gmail.com
}

needed to meet this demand. This is why concerns related to the security of energy supplies have become real national and international issues, and the support of RE has been identified as a requirement.

Furthermore, the choice to promote RE will not only lead to further modernization of the energy sector but will also support the economic development and sustainability objectives of the different countries [2]. Also one of the main objectives of the Sustainable Energy for All (SE4ALL) initiative launched by the United Nations in 2011 is to double the percentage of RE in the global energy mix by 
2030 [3]. In addition, the Energy Information Administration (EIA) reports that energy production from renewable sources has grown faster than from fossil fuels [4]. In this context, developed economies are promoting $\mathrm{RE}$ in order to strengthen the security of energy supply and control their greenhouse gas (GHG) emissions [5]. So, many governments around the world have then oriented their transition strategies towards more sustainable and affordable energy systems.

Morocco, whose energy resources are very limited, depends for more than $95 \%$ on the outside, which represents a quarter of total export revenues [6]. A situation of deficiency and need that is not without consequences; it has serious repercussions on the national economy, on the aggravation of the trade deficit and on consumer prices, thus impacting the financial balance of the State, the competitiveness of national firms and the purchasing power of citizens.

Aware of importance of $\mathrm{RE}$ in the socio-economic development of the territories, Morocco has devoted its efforts over the last two decades to ensure the establishment of a conducive environment for development of these energies through the implementation of policies to promote $\mathrm{RE}$. These policies are part of a program to diversify energy sources in order to improve economic growth and develop promising sectors.

Morocco that gives a special interest to clean energies to reconcile between socio-economic development and the fight against climate change, has implemented a "new national energy strategy" in March 2009, which aims to strengthen the security of supply, energy availability, enhancing the competitiveness of the productive sector and finally the protection of the environment, while committing to a real energy transformation that gives a major place to $\mathrm{RE}$ and Energy Efficiency (EE).

\subsection{Literature review of the impact of renewable energies on the economic development of the territory}

Studies have focused on studying the impact of renewable electricity support programs on the price of electricity. They have empirically analyzed the case of wind energy production in Spain. The results show that there is a negative correlation between the promotion of wind power and the price of electricity in general [7]. In addition, other studies have presented the analysis and results of the conception of a fully RE-based energy system in Denmark in 2050. The results of the energy system analysis model called "Energy PLAN" show that a 100\% RE-based energy system is technically possible in the future and may even have positive technological and socio-economic results [8]. The determination of the impact of $\mathrm{RE}$ on the economic development of a territory is possibly done by studying the impact of RE on economic indicators such as investment, the general level of prices, wages, energy prices and gross domestic product (GDP). However, most studies have focused simply on one indicator, which is GDP. The relationship between RE consumption and GDP has been widely examined by different empirical studies that analyze different countries and regions. Most empirical studies have found that there is a long-term causal link between RE consumption and GDP [9,10]. A study is carried out on the relationship between RE production and GDP by analyzing the correlation between RE production and economic growth in many blocks of the African continent. This study found that there is a positive correlation between RE production and GDP, except in the Southern African block where the correlation is negative [11]. Additional researches have studied the energydevelopment relationship for 15 countries of the European Union over the period 1990-2009, based on a multi-variable model including real production, capital, labor and consumption of renewable energy. According to their results, the consumption of renewable energy has a positive and significant effect on economic development only for several EU countries such as Bulgaria, Estonia, Poland and Slovenia [12]. In another component, United Nations Environment Program (UNEP) (2011), in its report published in February 2011, the authors argue that the transition to RE leads to a green economy strategy that creates green jobs and is essential for poverty eradication [13].

\subsection{Morocco's energy strategy on the move: A place of choice for renewable energies}

Lacking oil and gas resources, Morocco has begun in recent years to give high priority to the development of RE, the main engine of economic and social growth. The country's interest in the development of green energy stems from its desire to reduce its dependence on fossil energy resources, reduce its greenhouse gas (GHG) emissions and take advantage of its significant potential in RE, particularly for solar and wind energy. The new energy strategy launched in 2009 crowns this desire and reinforces the role of renewable energy in contributing to the security of supply and the availability of energy at relatively low costs.

\subsubsection{Main objectives and orientations of Morocco's energy} strategy

Due to the growing demand for energy and the heavy bill borne by public finances, Morocco adopted in 2009 an ambitious energy strategy that aims at four fundamental objectives and defines four strategic orientations: [14]

- Security of supply and availability of energy;

- Widespread access to energy at reasonable prices;

- Control of demand;

- Protection of the environment.

These objectives will be achieved essentially through the following orientations:

- An electrical mix optimized around reliable and competitive technological choices. Clean coal, the most available energy with the most stable prices and producing the cheapest KWh, forms the basis for basic production. The options for natural gas, nuclear power and direct combustion of oil shale remain open and their realization is conditioned by their long-term accessibility and availability, their technical and economic feasibility and their competitiveness. 
- A raising of domestic resources through the development of RE, which will enable Morocco to cover a substantial share of its energy needs, mitigate its energy dependence and reduce GHG emissions.

- An increased awareness of the issue of energy efficiency as the fastest and least expensive way to use and save energy and lower energy bills.

- Regional integration through the strengthening of interconnection and regional cooperation to support energy security, lower supply costs, expand trade, develop cooperation, intensify technology transfers and solidarity.

This strategy has been turned into accurate and quantified objectives and translated into clear roadmaps and real programs and projects that have been supported by a framework of legal, institutional and regulatory reform in order to implement them.

To implement its energy strategy, Morocco is carrying out several development projects in the clean energy sector such as NOOR Midelt, Aftissat in Boujdour, Haoum in Tangier, Abdelmoumen Pumped Energy Transfer Station (PETS) in Taroudant, NOOR Ouarzazate (including NOOR 1 its first phase which is our case study), etc., the objective being that renewable electricity represents $52 \%$ of the electricity produced in 2030 . So the question we will answer in this article is the following: "How does NOOR 1 project impact the economic development of the Moroccan territory in general and of the Southern region in particular?".

Regarding NOOR 1, it includes the installation of 500,000 parabolic mirrors arranged in 800 lines over an estimated area of $1308000 \mathrm{~m}^{2}$. The project is equipped with steel solar collectors that hold the mirrors and receivers in place. These $12-\mathrm{m}$ high glass panels follow the sun's movement to capture and concentrate radiation throughout the daily solar cycle (their temperature is $\left.393{ }^{\circ} \mathrm{C}\right)$. Electricity is generated when the concentrated light is converted to heat, which drives a steam turbine connected to an electrical energy generator and powers the thermal storage system. The energy storage system integrated in the case of NOOR 1 is the melted salt system which allows the electricity to be generated for an additional $3 \mathrm{~h}^{1}$. This system makes it possible to protect against the variability of direct solar radiation and thus prevent the risks associated with variations in sunshine.

Equipment and associated utilities [15]:

- Synthetic oil: In the case of the choice of parabolic trough technology, the heat transfer fluid used is synthetic oil. Between 15000 and 17000 tons of synthetic oil are required. This oil can reach high temperatures $\left(400^{\circ} \mathrm{C}\right)$ and solidifies at about $12{ }^{\circ} \mathrm{C}$. Its viscosity is high at room temperature and limits the effects of infiltration.

- Fossil fuel requirements: CSP plants also use fossil fuels to supplement solar production during periods of low solar radiation. Fossil fuel energy is necessary to keep the molten salt at a high temperature to keep it liquid (solidification at $110^{\circ} \mathrm{C}$ ) and to maintain the oil

\footnotetext{
${ }^{1}$ The storage will be done by using molten salts, these salts are a mixture of $60 \%$ sodium nitrate and $40 \%$ potassium nitrate.
}

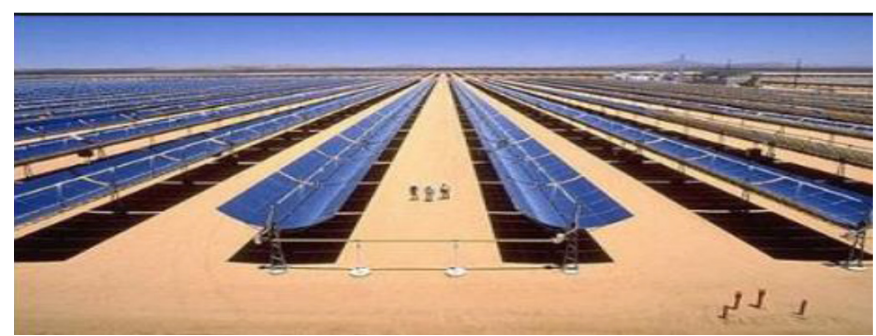

Fig. 1. NOOR 1 (Concentrated Solar Power) installation.

temperature above its minimum working temperature $\left(8^{\circ} \mathrm{C}\right.$ for synthetic oil) and to power the pumps during the night to ensure the circulation of the oil in the circuits.

- The needs and supply of water: for NOOR 1 the water supply is necessary to ensure:

- Wet cooling/condensation system: A wet cooling tower is used to extract and condense steam from the steam turbine by circulating it through cold water.

- Auxiliary Cooling System: This cooling system will release waste heat that will accumulate when operating equipment such as electric generator coolers, air compressor coolers, feedwater pumps, condensate pumps and thermal oil pumps.

\section{Methodology and materials}

\subsection{Field study: NOOR 1 (concentrated solar power)- South Morocco region}

Coordinated by the Moroccan Agency for Solar Energy (MASEN), NOOR 1 is a 160 MW CSP plant equipped with a parabolic mirror array, a 3-h salt thermal storage system, and a water-cooled steam circuit (Fig. 1).

The main advantage of this technology is the production of electricity not only during sunny hours, but also after sunset by storing the heat in the dissolved salt.

It is worth mentioning that the choice of setting up the NOOR 1 projectin the southern region of Morocco was mainly due to the high sunshine levels characteristic of the region. With a DNI (Direct Normal Irradiation) of about $2420 \mathrm{kWh} / \mathrm{m}^{2} / \mathrm{yr}$, so the area has a large solar resource.

\subsection{Techniques and methods of data collected and content analysis}

A list of the various impact indicators used in the qualitative analysis is drawn from the DPSIR « Driving Forces; Pressure; State; Impact; Response » model and adapted to our case study according to the following table [16] (Tab. 1):

The interview is our main source of data collection. Semi-directive interviews were conducted with several profiles that have a direct or indirect involvement with NOOR 1. The data collected comes from information obtained during the face-to-face exchange with different 
Table 1. Economic development indicators used in the qualitative analysis.

\begin{tabular}{lll}
\hline & Indicator & objective \\
\hline & Industrial integration & \\
& Economic Attractiveness & \\
& Consumption of goods and services & \\
& Intensity in road traffic & - Sustainable economic growth $=$ \\
& Regional infrastructure & sustainable or viable \\
& Competitiveness & - Mobility and territorial activity \\
Economic impact of NOOR 1 & Energy consumption and production & - Mobility fulfilled by sustainable modes \\
& Production of goods and services & - Maximal use of energy from renewable \\
& Activity of local companies & resources \\
& Agriculture & - Investments promoting sustainable \\
& Technological development & \\
& Opening up of the territory & \\
& Tourism & \\
\hline
\end{tabular}

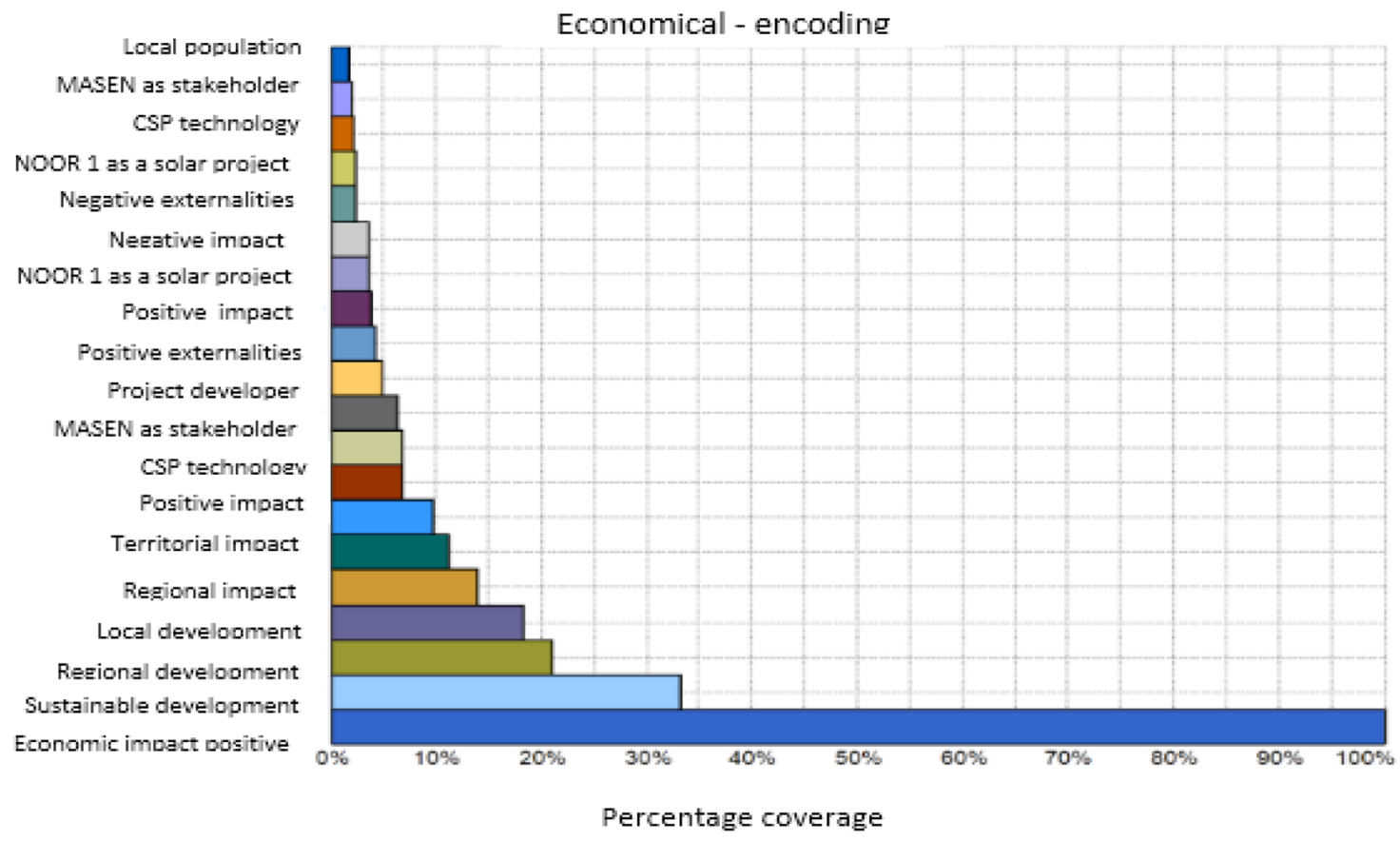

Fig. 2. Encoding by source - economic dimension.

respondents (semi-directive interviews), who were asked about the installation of NOOR 1 in the South region, its operating mechanism, its technology, its economic consequences on local communities and others.

The codification and analysis approach adopted is based entirely on Nvivo 12 software (Fig. 2).

The encoding by source allowed the gathering of all the information from the semi-directive interviews and documentation. We find that this information covers all the factors (at different percentages of coverage) that can explain the economic impact of NOOR 1 on the southern region.

\section{Results and discussions}

To classify and evaluate the significance of the economic impact of NOOR 1 on the southern region, we used the following reading grids:

\subsection{Significance of impact}

Based on the processing of data collected through interviews (verbatims) and documentation in Nvivo 12, we were able to classify each impact in accordance with its order of importance. Five levels of impact significance were 


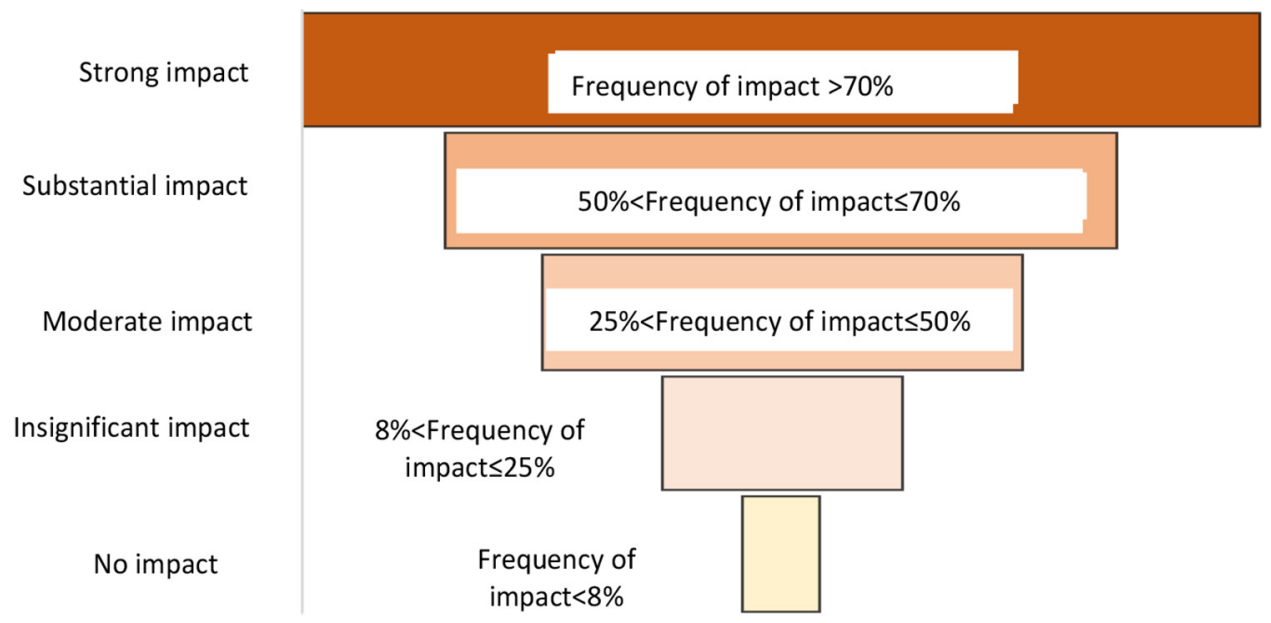

Fig. 3. Impact significance reading grid.

therefore adopted: "Strong", "Substantial", "Moderate", "Insignificant" and "no impact" as follows (Fig. 3):

\subsection{Impact status and impact type}

There are two categories of impact status: either an effect on the chosen indicator is tangible, real and concrete: in this case the impact is classified as "Observed Impact", or we anticipate results and effects that will be observed in the future if we use current data and achievements, in which case the impact will be classified as "Anticipated Impact". Also, we have considered two kinds of impact: "positive" symbolized by the $(+)$ sign and "negative" symbolized by the $(-)$ sign.

\begin{tabular}{lll}
\hline Status & Type \\
\hline Observed Impact & Positive impact & + \\
Anticipated Impact & Negative impact & - \\
\hline
\end{tabular}

\subsection{Results analysis}

See Table 2 .

\section{Conclusion}

In Morocco, the RE technologies's rollout has significantlygrown in recent decades to meet the growing demand for energy and to replace the use of fossil fuels. Furthermore, it is important to specify that no power plant in the world, whatever the energy source, produces the maximum of its theoretical capacity. Unlike other solar power plants in the world, NOOR 1 has the advantage of producing electricity at least $3 \mathrm{~h}$ after sunset. This is possible because Morocco has indeed opted for a technology (CSP) still not widely used, which is certainly more expensive, but which allows to optimize energy. At the industry sector, CSP technologies are still underdeveloped: they therefore represent

Table 2. Review of results related to the economic impact of NOOR 1 on the Southern Region.

\begin{tabular}{|c|c|c|c|c|c|}
\hline Economic impact & Status & Type & $\begin{array}{l}\text { Initial state } \\
\text { in the region }\end{array}$ & $\begin{array}{l}\text { Impact } \\
\text { significance }\end{array}$ & Details \\
\hline $\begin{array}{l}\text { Industrial } \\
\text { integration and } \\
\text { competitiveness }\end{array}$ & Observed & + & Insignificant & Moderate & $\begin{array}{l}\text { Use of local equipment and services for } \\
\text { the construction and operation of } \\
\text { NOOR1. } \\
\text { Launch of new industrial activities such } \\
\text { as the production of "torque tubes". } \\
\text { Strengthening the high-tech capacity of } \\
\text { local firms through knowledge } \\
\text { collaboration and increased technology } \\
\text { in association with foreign firms } \\
\text { increases the capacity of local industry. }\end{array}$ \\
\hline $\begin{array}{l}\text { Improvement of } \\
\text { activity and } \\
\text { economic } \\
\text { attractiveness }\end{array}$ & Observed & + & Insignificant & Moderate & $\begin{array}{l}\text { Individual small business development. } \\
\text { Very significant training and support are } \\
\text { provided, allowing the region's young } \\
\text { people to progress, with the necessary }\end{array}$ \\
\hline
\end{tabular}


Table 2. (continued).

\begin{tabular}{|c|c|c|c|c|}
\hline Economic impact & Status & Type & $\begin{array}{l}\text { Initial state } \\
\text { in the region }\end{array}$ & $\begin{array}{l}\text { Impact } \\
\text { significance }\end{array}$ \\
\hline
\end{tabular}

\section{Transportation Intensity \\ Observed + Moderate Strong}

Development of regional infrastructure and availability of regional services
Change in Energy Consumption and Production
Improvement of production and consumption of goods and services

Improvement of the activities of local businesses

Observed + Insignificant Substantial

Anticipate-d + Insignificant Substantial

Observed + Insignificant Substantial

Observed + Insignificant Substantial
Details

guidance and support offered by the regional investment center.

Industrial consolidation enables to attract local companies to invest in new production lines and encourages international investors to create local branch offices.

Improvement of nearby transport infrastructure facilitated access to the project site Many vehicles (buses, small-buses, cars...) are mobilized to transport thousands of workers every day.

Carrying out investments for the benefit of the community and the communities concerned thanks to the purchase price of the project land.

The investment and potential multiplier effects of NOOR 1 have stimulated socio-economic and regional infrastructure development. Improvement of living conditions in adjacent communities.

Drainage and evacuation works for rainwater.

Implementation of Telecom networks.

Good quality of electricity supplied at the peak due to NOOR 1 (CSP) technology.

Contribution to domestic energy needs. Ensure the security of electricity supply to the market.

Economic competitiveness of the electricity produced by thermodynamic solar energy which can deal with fossil fuels within 10-15 yrs.

Increase in the price per square meter in housing.

Unprecedented activity in the rental market.

Development of infrastructures to ensure housing and food for workers.

Increase in the activity of existing local companies for the supply of materials and equipment necessary for the activity, as well as for the daily maintenance of the equipment. Companies for the assembly of the solar field are created on site.

Development of industrial activities in the region via the participation of local small and medium companies in the different services of maintenance, guarding, industrial cleaning. 
Table 2. (continued).

\begin{tabular}{|c|c|c|c|c|c|}
\hline Economic impact & Status & Type & $\begin{array}{l}\text { Initial state } \\
\text { in the region }\end{array}$ & $\begin{array}{l}\text { Impact } \\
\text { significance }\end{array}$ & Details \\
\hline $\begin{array}{l}\text { Improvement of } \\
\text { agriculture }\end{array}$ & Observed & + & Insignificant & Moderate & $\begin{array}{l}\text { Improved agricultural, environmental, } \\
\text { economic and social performance } \\
\text { through skills transfer. } \\
\text { Development and enhancement of the } \\
\text { palm grove in the Ghessate village. } \\
\text { Substantial increase in date yields from } \\
10 \mathrm{~kg} / \text { tree to } 100 \mathrm{~kg} \text { per tree. }\end{array}$ \\
\hline $\begin{array}{l}\text { Technology } \\
\text { development }\end{array}$ & Observed & + & None & Strong & $\begin{array}{l}\text { Development of leading national } \\
\text { expertise } \\
\text { Training of technicians in new RE and } \\
\text { non-polluting technologies. } \\
\text { Acquisition of expertise by local } \\
\text { employees regarding CSP technology in } \\
\text { particular. } \\
\text { Technology transfer in the field of solar } \\
\text { energy }\end{array}$ \\
\hline $\begin{array}{l}\text { Opening up of the } \\
\text { territory }\end{array}$ & Observed & + & Insignificant & Substantial & $\begin{array}{l}\text { Improvement of electrification rates in } \\
\text { the region's rural, semi-urban areas. } \\
\text { To allow access to electric energy to } \\
\text { excluded social categories. } \\
\text { Reducing the isolation of different } \\
\text { communities by developing roads to } \\
\text { facilitate the movement of the region's } \\
\text { inhabitants. } \\
\text { Providing a connection to drinking } \\
\text { water and telecom networks. }\end{array}$ \\
\hline $\begin{array}{l}\text { Economic } \\
\text { exclusion of small } \\
\text { and medium firms }\end{array}$ & Anticipated & - & None & Moderate & $\begin{array}{l}\text { Although the local content requirement } \\
\text { was seen as beneficial, many small and } \\
\text { medium firms complained that their } \\
\text { chances of business opportunities are } \\
\text { limited due to their lack of capacity } \\
\text { compared to foreign firms and foreign } \\
\text { workers more qualified. }\end{array}$ \\
\hline $\begin{array}{l}\text { Improvement of } \\
\text { tourism }\end{array}$ & Anticipated & + & Substantial & Insignificant & $\begin{array}{l}\text { Attractiveness of domestic and } \\
\text { international tourists who come to } \\
\text { discover the facilities of the NOOR } 1 \\
\text { project. } \\
\text { Possibility of opening the project site to } \\
\text { visits by introducing it to the tourist } \\
\text { circuit. }\end{array}$ \\
\hline
\end{tabular}

\footnotetext{
*Helically welded and galvanized metal tubes that support the parabolic cylindrical mirrors, which are driven by automatic motors that
} allow the mirrors to follow the sun's rays at every moment and maximize their thermal efficiency.

a significant potential for the creation of new markets and are promising in terms of job creation, technology transfer and therefore economic and social development. A (RE) project such as NOOR 1 allows a better valorisation of the country's natural resources and contributes to the regional or even national economic development. Finally, this study shows that the implementation of a RE project is likely to promote economic development at the local and national level. It also provides a better understanding of the complex relationships between large RE facilities and the territories in which they are located.
The authors would like to thank the anonymous contributors for their various aids. The authors also express their gratitude to the many colleagues and organizations that openly shared data in this study.

\section{References}

1. A. Kitous, P. Criqui, E. Bellevrat, B. Château, Transformation patterns of the worldwide energy system - Scenarios for the century with the POLES model, Energy J. 31, 49-82 (2010) 
2. K. Kaygusuz, O. Yuksek, A. Sari, Renewable energy sources in the European union: markets and capacity, Energ. Sourc. Part B 2, 19-29 (2007)

3. Jr. Holliday, Sustaining human life through sustainable energy, Energy Strategy Rev. 2, 209-210 (2013)

4. World Energy Demand and Economic Outlook of the 2009 International Energy Outlook. www.eia.doe.gov/oiaf/ieo/ world.html (accessed May 7, 2020)

5. B. Moselle, Why support renewables? EPRG spring research seminar (University of Cambridge, UK, 2011)

6. Rapport du Ministère de l'Énergie, des Mines, et de l'Environnement (MEME), 2018. www.mem.gov.ma/ (accessed September 20, 2020)

7. D. Saenz, M. Gonzalo, D.-R. Gonzalez, I. Vizcaino, Analysing the impact of renewable electricity support schemes on power prices: the case of wind electricity in Spain, Energy Policy 36, 3345-3359 (2008)

8. B.V. Mathiesen, H. Lund, K. Karlsson, 100\% Renewable energy systems, climate mitigation and economic growth, Appl. Energy 88, 488-501 (2011)

9. N. Apergis, J.E. Payne, renewable and non-renewable electricity consumption-growth nexus: evidence from emerging market economies, Appl. Energy 88, 5226-5230 (2011)
10. C-T. Tugcu, I. Ozturk, A. Aslan, Renewable and nonrenewable energy consumption and economic growth relationship revisited: evidence from G7 countries, Energy Econ. 34, 1942-1950 (2012)

11. H. Abanda, A. Ng'ombe, R. Keivani, J. Tah, The link between renewable energy production and gross domestic product in Africa: a comparative study between1980 and 2008, Renew. Sustain. Energy Rev. 16, 2147-2153 (2012)

12. A. Alper, O. Oguz, The role of renewable energy consumption in economic growth: evidence from asymmetric causality, Renew. Sustain.Energy Rev. 60, 953-959 (2016)

13. United Nations Environment Programme (UNEP), Towards a Green Economy: Pathways to Sustainable Development and Poverty Eradication. A Synthesis for Policy Maker (UNEP, France, 2011). www.unep.org/greeneconomy/Por tals/88/documents/ger/GER_synthesis_en.pdf (accessed November 4, 2020)

14. Report of the Ministry of Energy, Mines, Water and Environment (MEMEE), (2011). www.mem.gov.ma/

15. 5 Capitals. Ouarzazate Solar Power Complex - SESIA, Environmental \& management consulting, (2012)

16. X. Delache, Environmental indicators: context, practices and issues raised for the evaluation of public policies, J. Financ. Econ. 6, 269-282 (2002)

Cite this article as: Amale Laaroussi, Abdelrhani Bouayad, Zakaria Lissaneddine, Lalla Amina Alaoui, Impact study of NOOR 1 project on the Moroccan territorial economic development, Renew. Energy Environ. Sustain. 6, 8 (2021) 